\title{
Comparison of diabetic patients' attitude and practice on medicinal herbs consumption and classical treatment in type 2 diabetes and related factors
}

\begin{abstract}
Background: Medicinal herbs are used in traditional medicine to control and treat many diseases, including diabetes. The use of medicinal plants by diabetic patients has increased dramatically over the past decade.

Methods: From diabetic patients covered by Kermanshah Diabetes Center, 51 patients were selected for each of the three groups (herbal medicine, drug therapy, and combination therapy) of type 2 diabetic patients (151 patients in total). After completing the questionnaire, their attitude and practice were compared. Effective factors were also analyzed using chisquare, t-test and one-way ANOVA.
\end{abstract}

Results: Significant statistical differences were reported between the mean and standard deviation of patients' attitude toward herbal medicines in the treatment of type 2 diabetes in the herbal (17.2 \pm 0.8$)$, medicinal $(9.7 \pm 2.7)$ and combination group $(15.4 \pm 2.3)(P<0.001)$. There was no significant relationship between the level of positive attitude to herbal treatment with age, sex, education level, marital status, occupation and family history of diabetes. But this relationship was significant for the duration of disease and duration of treatment $(P=0.01)$. Cinnamon, green tea, ginger, fenugreek, nettle, and turmeric were the most commonly used medicinal herbs.

Conclusions: The results of this study show that diabetic patients with the use of herbal medicine had a better attitude towards the use of herbal medicines than patients with combination or drug treatment alone. Patients with shorter duration of treatment and illness had higher attitudes and performance than herbal medicines.

Keywords: diabetes, attitude, medicinal plants, type 2 diabetes
Volume 8 Issue 3 - 2020

\author{
Azizi Ali, Shaheb-Hmaei Pegah \\ Department of Community and Family Medicine, Kermanshah \\ University of Medical Science, Iran
}

Correspondence: Azizi Ali, Department of Community and Family Medicine, Kermanshah University of Medical Science, P.O.BOX: | 568- Kermanshah, Iran, Tel +989|8339|884,

Email aliazizi@kums.ac.ir, atwsm296@gmail.com

Received: April 14, 2020 | Published: May 22, 2020

\section{Introduction}

Diabetes is a silent epidemic that is becoming more and more prevalent with changing patterns of life. This change includes an inappropriate diet that results in serious Complications to the person. Failure to control diabetes can cause serious damage to organs such as the brain, heart, kidneys, eyes and lower limbs and can eventually lead to death. ${ }^{1}$ Type 2 diabetes (DM2) is a complex, multiphase disease that occurs when pancreatic beta cells are unable to release sufficient insulin to meet the body's metabolic needs due to insulin resistance in the peripheral tissues, and this leads to Hyperglycemia. ${ }^{2}$ This type of diabetes often occurs after the age of 40 and above. ${ }^{3}$ Therapeutic approaches in diabetic patients have two goals: control of blood sugar, stopping long-term side effects. Drug therapy is an inevitable treatment for these patients. Oral and insulin medications (respectively) are the most important type 2 diabetes control drugs. ${ }^{4}$ But there are various medicinal plants in most parts of the world that can help control the blood sugar of a diabetic patient by lowering blood sugar. The World Health Organization (WHO) considers complementary and alternative medicine in each country a wide range of therapies that are not formally incorporated into that country's health system. These therapies have either come from past medical traditions or are based on contemporary concepts.
According to the American Society of Complementary and Alternative Medicine, complementary Medicine is divided into five groups, alternative medicine systems (Traditional Chinese Medicine, Indian and Homeopathy), mind-body interventions, energy therapies, manipulative and body-based methods (Massage and Chiropractic) and biologically based treatments (herbal remedies and dietary supplements). Medicinal plants are rich sources of natural antioxidants and have been used in traditional medicine to control and treat many diseases. ${ }^{5,6}$ Varieties of plant-derived materials indicate a variety of biological activities in which they include alkaloids, glycosides, polysaccharides, peptidoglycans, hypoglycans, guanidine, steroids, carbohydrates, glycopeptides, terpenoids, Amines, and inorganic ions have anti-diabetic activity. ${ }^{7}$ On the other hand, the cost of treatment with chemical drugs is very high, especially for those who do not use the various insurance facilities and have to buy drugs at an affordable price, so using herbal medicines will be cheaper and at the same time cheaper. Using herbal remedies does not necessarily mean rejecting chemicals completely and having antiscience and anti-medical thinking, but in some cases using traditional medicine may be a better way to treat some diseases. Given people's willingness to use medicinal plants in the treatment of type 2 diabetes in most geographical areas, this study was conducted to compare the attitude and practice of diabetic patients regarding medicinal herbs 
consumption, classic therapy and concomitant (herbal and medicinal) treatment of type 2 diabetes in western Iran.

\section{Materials and methods}

The study population was diabetic patients covered by Kermanshah Diabetes Center in 2019. Using the sample size formula of comparative studies and the results of similar studies, ${ }^{8,9}$ taking into account $\alpha=0.05$ and $\beta=0.15$, the minimum sample size for each group (herbal treatment, medication, and combination therapy) was 25 persons. To increase the accuracy of the study, 51patients in each group and 153 in total were included in the study. Inclusion criteria were over 18years of age, willingness to participate in the study, definitive diagnosis of type 2 diabetes, insensitivity to medication for drug treatment and no diabetes Complications.

$$
n=\frac{\left(z\left(1-\frac{\alpha}{r}\right)+z\left({ }^{\prime}-\beta\right)\right)^{r}\left(\left(p^{\top} * q^{\prime}\right)+\left(p^{r} * q^{r}\right)\right)}{\left(p^{r}-p^{\prime}\right)^{r}}
$$

From diabetic patients covered by Kermanshah Diabetes Center, 153 patients were selected by systematic random sampling ( 51 for each group) and completed a questionnaire. The questionnaire consisted of three sections. The first section included demographic information and the second section included questions about patients' attitudes toward the treatments, which included 6 questions on a Likert scale (agree, disagree and disagree). All questions (except one question that was reversed) were rated for answer 3, disagree with score 1 , and answer "no" with score 2 . The total score of attitude questions ranged from 6 to 18. The third section was related to patients' performance questions, including how to get acquainted with the treatment, how to use the drug and, ultimately, patient satisfaction. Proposal and questionnaire of this study were approved by the Research Ethics Committee of Kermanshah University of Medical Sciences under IR.KUMS.REC.1397.722. Data analysis was performed using SPSS V.22 software, using $\mathrm{x}^{2}$, t-test, and one-way ANOVA at the significant level of 0.05 .

\section{Results}

This cross-sectional study was conducted with the participation of 151 people with type 2 diabetes in three groups (51herbal medicines, classical treatments, and herbal and medicinal treatments). The mean age of the patients was $57.79 \pm 11.91$, the mean duration of diabetes was $9.06 \pm 8.38$ and the mean duration of diabetes treatment was $7.56 \pm 6.52$ years. $71.5 \%$ (110patients) were female, $84.3 \%$ (129persons) married, $72.5 \%$ (111 persons) unemployed and housewives and 54.2\% (83persons) had a family history of diabetes (Table 1). Chi-square test showed that the patients in the three groups did not have a significant difference in the frequency of sex, occupation and family history of diabetes. But one-way ANOVA test showed a significant difference in mean age of patients $(\mathrm{F}=4.25, P<0.001)$, duration of diabetes $(\mathrm{F}=23.92, P<0.001)$ and duration of treatment $(\mathrm{F}=20.5, P<0.001)$ in three groups (Table 1). The mean age (60.92years), duration of diabetes (13.35years) and duration of treatment (11.31years) in the combination therapy group were higher than the mean of the herbal and drug treatment groups, respectively. Tukey post hoc test showed a significant difference.

Patients' satisfaction was $95.9 \%$ with herbal treatment, $84.3 \%$ with combination therapy and $54.9 \%$ with medication; Chi-square test showed that the three groups had a statistically significant difference in satisfaction with treatment $\left(\chi^{2}=23.6, \mathrm{df}=2, \mathbf{P}<0.001=\right)$. Most of the patients in the herbal treatment group agreed to higher treatment speed $(52.9 \%)$, better accessibility $(62.7 \%)$ and lower cost $(60.1 \%)$ (Table $1)$. In the herbal treatment group, parents and acquaintances were the most important source of knowledge (45.1\%) and in the combination therapy group, $60 \%$ were friends and acquaintances; Chi-square test showed a statistically significant difference in the source of treatment knowledge in the three groups $(P<0.001)$. Patients' consumption of herbal medicine in the tail form was $56.8 \%$ and combined consumption was $7.16 \%$ (Table 1$)$.

Table I Comparison of underlying variables and attitude score in three groups of patients $(n=5 \mathrm{I}$ in each group)

\begin{tabular}{|c|c|c|c|c|c|c|}
\hline & & \multicolumn{4}{|c|}{ Type of treatment } & \multirow[b]{2}{*}{$\mathbf{P}$} \\
\hline & & $\begin{array}{l}\text { Herbal } \\
\mathrm{n}(\%)\end{array}$ & $\begin{array}{l}\text { Medicinal } \\
\mathrm{n}(\%)\end{array}$ & $\begin{array}{l}\text { Herbal and } \\
\text { medicinal } \mathbf{n}(\%)\end{array}$ & $\begin{array}{l}\text { Total } \\
\text { n(\%) }\end{array}$ & \\
\hline \multirow{2}{*}{ Sex } & Man & II (25.6) & $19(44.2)$ & $13(30.2)$ & $43(100)$ & \multirow{2}{*}{0.1} \\
\hline & Female & $40(36.3)$ & $32(29.1)$ & $38(34.5)$ & $110(100)$ & \\
\hline \multirow{2}{*}{ marital status } & Single & II(47.8) & $5(21.7)$ & $7(30.4)$ & $23(100)$ & \multirow{2}{*}{0.4} \\
\hline & Married & $40(31)$ & $46(35.6)$ & $43(33.3)$ & $129(100)$ & \\
\hline \multirow{3}{*}{ Job } & Unemployed & $38(34.2)$ & $34(30.6)$ & $39(35.1)$ & $111(100)$ & \multirow{3}{*}{0.7} \\
\hline & Free & $8(32)$ & $10(40)$ & $7(28)$ & $25(100)$ & \\
\hline & Employee & $5(29.4)$ & $7(4 \mid .2)$ & $5(29.4)$ & $17(100)$ & \\
\hline \multirow{2}{*}{$\begin{array}{l}\text { Family history of } \\
\text { diabetes }\end{array}$} & yes & $26(31.3)$ & $29(34.9)$ & $28(33.7)$ & $83(100)$ & \multirow{2}{*}{0.8} \\
\hline & No & $25(35.7)$ & $22(31.4)$ & $23(32.9)$ & $70(100)$ & \\
\hline \multirow{5}{*}{$\begin{array}{l}\text { How acquainted with } \\
\text { treatment }\end{array}$} & Parents and relatives & $23(71.9)$ & $\mathrm{I}(3.1)$ & $8(25)$ & $32(100)$ & \multirow{5}{*}{$<0.001$} \\
\hline & Health personnel & $3(13)$ & $7(30.4)$ & $13(56.6)$ & $23(100)$ & \\
\hline & Friends & $10(18.2)$ & $3(54.5)$ & $15(27.3)$ & $55(100)$ & \\
\hline & media & $4(50)$ & $3(37.5)$ & $\mathrm{I}(12.5)$ & $8(100)$ & \\
\hline & A few cases & $\mid I(2 \mid .6)$ & $9(18)$ & $14(27.5)$ & $34(22.4)$ & \\
\hline
\end{tabular}


Table Continued..

\begin{tabular}{|c|c|c|c|c|c|c|}
\hline & & \multicolumn{4}{|c|}{ Type of treatment } & \multirow[b]{2}{*}{$P$} \\
\hline & & $\begin{array}{l}\text { Herbal } \\
\mathrm{n}(\%)\end{array}$ & $\begin{array}{l}\text { Medicinal } \\
\text { n(\%) }\end{array}$ & $\begin{array}{l}\text { Herbal and } \\
\text { medicinal } n(\%)\end{array}$ & $\begin{array}{l}\text { Total } \\
\text { n(\%) }\end{array}$ & \\
\hline \multirow{4}{*}{$\begin{array}{l}\text { How to use herbal } \\
\text { medicine }\end{array}$} & Brewed, boiled & $33(56.9)$ & - & $25(43.1)$ & $58(100)$ & \multirow{4}{*}{0.3} \\
\hline & powder & $5(4 \mid .7)$ & - & $7(58.3)$ & $12(100)$ & \\
\hline & Sweat & $6(40)$ & - & $9(60)$ & $15(100)$ & \\
\hline & Combined & $7(4 \mid .2)$ & - & $10(58.8)$ & $17(100)$ & \\
\hline \multirow{3}{*}{ Speed of treatment } & agree & $36(39.6)$ & $28(30.7)$ & $27(29.7)$ & $91(100)$ & \multirow{3}{*}{0.009} \\
\hline & No idea & $13(40.6)$ & $8(25)$ & II(34.4) & $32(100)$ & \\
\hline & disagree & $2(6.7)$ & $15(50)$ & $13(43.3)$ & $30(100)$ & \\
\hline \multirow{3}{*}{$\begin{array}{l}\text { Availability of } \\
\text { treatment }\end{array}$} & agree & $45(42.1)$ & $30(28)$ & $32(29.9)$ & $107(100)$ & \multirow{3}{*}{0.01} \\
\hline & No idea & $6(42.9)$ & $2(14.3)$ & $6(42.8)$ & $14(100)$ & \\
\hline & disagree & - & $19(59.4)$ & 13(40.6) & $32(100)$ & \\
\hline \multirow{3}{*}{ Low cost of treatment } & agree & $40(43.5)$ & $23(25)$ & $29(31.5)$ & $92(100)$ & \multirow{3}{*}{0.007} \\
\hline & No idea & $5(33.3)$ & $5(33.3)$ & $5(33.3)$ & $15(100)$ & \\
\hline & disagree & $6(13)$ & $23(50)$ & $17(37)$ & $46(100)$ & \\
\hline \multirow{2}{*}{$\begin{array}{l}\text { Satisfaction with } \\
\text { treatment }\end{array}$} & yes & $47(39.8)$ & $28(23.7)$ & $43(36.5)$ & $118(100)$ & \multirow{2}{*}{$<0.001$} \\
\hline & No & $2(6.5)$ & $21(67.7)$ & $8(25.8)$ & $31(100)$ & \\
\hline Age & Mean $\pm S D$ & $54.4 \pm 11.2$ & $58.1 \pm 11.6$ & $60.9 \pm 11.3$ & $57.8 \pm 11.5$ & $<0.01$ \\
\hline Duration (years) & Mean \pm SD & $3.5 \pm 4.2$ & $10.2 \pm 8.6$ & $13.35 \pm 8.36$ & $9.1 \pm 8.4$ & $<0.001$ \\
\hline $\begin{array}{l}\text { Duration of treatment } \\
\text { (years) }\end{array}$ & Mean $\pm S D$ & $3 \pm 2.4$ & $8.4 \pm 7.8$ & $11.3 \pm 8.1$ & $7.6 \pm 7.4$ & $<0.001$ \\
\hline Attitude total score & Mean $\pm S D$ & $17.2 \pm 0.8$ & $9.7 \pm 2.7$ & $15.4 \pm 2.3$ & $\mid 4.1 \pm 3.8$ & $<0.001$ \\
\hline
\end{tabular}

In the present study, cinnamon (26.5\%), green tea (14.7\%), ginger $(9.8 \%)$, fenugreek $(9.8 \%)$, nettle $(6.9 \%)$ and turmeric $(9.9 \%)$ were respectively. $6 \%$ ) had the highest consumption for the treatment of type 2 diabetes in patients taking herbal medicines (Table 2). In the group of patients taking medication, metformin $(38.2 \%)$ was the most common drug, followed by metformin and glibenclamide (19.6\%), metformin and insulin (11.8\%), glibenclamide (11.8\%). 8.8\%), insulin $(4.9 \%)$ was most commonly used by patients. $96 \%$ of patients using herbal medicines and $66.7 \%$ of patients with combination therapy and $31.4 \%$ of the classical drug group had a desirable attitude toward herbal diabetes treatment (Table 3). Chi-square test showed that the percentage of favorable attitude in patients with medicinal herbs was significantly higher than the other two groups $\left(\chi^{2}=110.8\right.$, $\mathrm{df}=4, \mathrm{P}<0.001)$. Also, the Chi-square test did not show a significant relationship between the level of desirable attitude to herbal treatment with age, sex, education level, marital status, job and family history of diabetes. But this association was significant for the duration of diabetes and its treatment. The most favorable attitude was observed in patients with disease duration less than 6years $(67.1 \%)\left(\chi^{2}=8.4, \mathrm{df}=2\right.$, $P<0.01)$ and treatment duration less than 5years $(71.1 \%)\left(\chi^{2}=14.3\right.$, $\mathrm{df}=2, P<0.001) \quad($ Table 4); ANOVA test showed that there was a statistically significant difference between patients' attitudes in the three treatment groups. The Tukey test showed a significant difference between the mean scores of the attitude of the three groups of herbal (17.2), medicinal (9.7) and combination (15.4) groups (Table 1).
Table 2 Frequency distribution of herbal medicinal plants in herbal and combined therapy groups

\begin{tabular}{llll}
\hline & \multicolumn{2}{l}{ Type of treatment } & \\
\cline { 2 - 3 } & $\begin{array}{l}\text { Herbal } \\
\mathbf{n}(\%)\end{array}$ & $\begin{array}{l}\text { Herbal and } \\
\text { medicinal } \\
\mathbf{n}(\%)\end{array}$ & $\begin{array}{l}\text { Total } \\
\mathbf{n}(\%)\end{array}$ \\
\hline Cinnamon & $\mathrm{I}(27.4)$ & $\mathrm{I} 3(25.4)$ & $27(26.5)$ \\
Green tea & $7(13.7)$ & $8(15.7)$ & $15(14.7)$ \\
Ginger & $6(I I .8)$ & $4(7.8)$ & $10(9.8)$ \\
Fenugreek & $3(5.9)$ & $7(13.7)$ & $10(9.8)$ \\
Nettle & $4(7.8)$ & $3(5.9)$ & $7(6.9)$ \\
Turmeric & $4(7.8)$ & $3(5.9)$ & $7(6.9)$ \\
curry powder & $3(5.9)$ & $2(3.9)$ & $5(4.9)$ \\
Garlic & $\mathrm{I}(2)$ & $4(7.8)$ & $5(4.9)$ \\
Okra & $2(3.9)$ & $2(3.9)$ & $4(3.9)$ \\
Chamomile & $2(3.9)$ & $\mathrm{I}(2)$ & $3(2.9)$ \\
Cumin & $2(3.9)$ & $\mathrm{I}(2)$ & $3(2.9)$ \\
Purslane & $\mathrm{I}(2)$ & $\mathrm{I}(2)$ & $2(2)$ \\
Pune & $\mathrm{I}(2)$ & $\mathrm{I}(2)$ & $2(2)$ \\
Sour tea & $\mathrm{I}(2)$ & $\mathrm{I}(2)$ & $2(2)$ \\
Total & $5 \mathrm{I}(100)$ & $5 \mathrm{I}(100)$ & $102(100)$ \\
\hline
\end{tabular}


Table 3 Determining the factors associated with a positive attitude towards herbal treatment

\begin{tabular}{|c|c|c|c|c|c|c|}
\hline & & \multicolumn{4}{|c|}{ Type of treatment } & \multirow[b]{2}{*}{$P$} \\
\hline & & $\begin{array}{l}\text { Poor } \\
\text { n(\%) }\end{array}$ & $\begin{array}{l}\text { Average } \\
\mathrm{n}(\%)\end{array}$ & $\begin{array}{l}\text { Desired } \\
\text { n(\%) }\end{array}$ & $\begin{array}{l}\text { Total } \\
\text { n(\%) }\end{array}$ & \\
\hline \multirow{2}{*}{ Sex } & Man & $14(32.6)$ & $9(20.9)$ & $2(46.5)$ & $43(100)$ & \multirow{2}{*}{0.2} \\
\hline & Female & $23(20.9)$ & $21(19.1)$ & $66(60)$ & $110(100)$ & \\
\hline \multirow{2}{*}{ marital status } & Single & $5(28.3)$ & $2(8.3)$ & $17(70.8)$ & $24(100)$ & \multirow{2}{*}{0.06} \\
\hline & Married & $32(24.8)$ & $28(21.7)$ & $69(53.5)$ & $129(100)$ & \\
\hline \multirow{3}{*}{ Job } & Unemployed & $24(21.6)$ & $24(18.9)$ & $66(59.5)$ & $\mathrm{III}(100)$ & \multirow{3}{*}{0.2} \\
\hline & Free & $10(40)$ & $3(12)$ & $12(48)$ & $25(100)$ & \\
\hline & Employee & $3(17.6)$ & $6(35.3)$ & $8(47.1)$ & $17(100)$ & \\
\hline \multirow{3}{*}{ education } & High school & $14(32.6)$ & $9(20.9)$ & $22(46.5)$ & $45(100)$ & \multirow{3}{*}{0.06} \\
\hline & Diploma & $20(26)$ & $14(18.2)$ & $43(55.8)$ & $77(100)$ & \\
\hline & Academic & $10(32.6)$ & $7(22.6)$ & $14(45.2)$ & $31(100)$ & \\
\hline \multirow{2}{*}{ Family history of diabetes } & yes & $23(27.7)$ & $15(18.1)$ & $45(54.2)$ & $83(100)$ & \multirow{2}{*}{0.5} \\
\hline & No & $14(20)$ & $15(21.4)$ & $4 I(58.6)$ & $70(100)$ & \\
\hline \multirow{2}{*}{ Age } & $<58$ years & $17(22.4)$ & $16(21.1)$ & $43(56.6)$ & $76(100)$ & \multirow{2}{*}{0.8} \\
\hline & 58years and over & $20(26)$ & $14(\mid 8.2)$ & $43(55.8)$ & $77(100)$ & \\
\hline \multirow{2}{*}{ Duration (years) } & Less than 6years & $16(21.1)$ & $9(11.8)$ & $5 I(67.1)$ & $76(100)$ & \multirow{2}{*}{0.01} \\
\hline & 6years and more & $21(27.3)$ & $21(27.3)$ & $35(45.5)$ & $77(100)$ & \\
\hline \multirow{2}{*}{ Duration of treatment (years) } & Less than 5years & I4(I8.4) & $8(10.5)$ & $54(71.1)$ & $76(100)$ & \multirow{2}{*}{0.001} \\
\hline & $5 y e a r s$ and more & $23(29.9)$ & $22(28.6)$ & $32(41.6)$ & $77(100)$ & \\
\hline \multirow{3}{*}{ Type of treatment } & herbal & $0(0)$ & $2(3.9)$ & $49(96.1)$ & $51(100)$ & \multirow{3}{*}{$<0.001$} \\
\hline & Medicinal & $35(68.6)$ & $13(25.5)$ & $3(5.9)$ & $5 I(100)$ & \\
\hline & Herbal and medicinal & $2(3.9)$ & $15(29.4)$ & $34(66.7)$ & $5 I(100)$ & \\
\hline
\end{tabular}

\section{Discussion}

The purpose of this study was to compare the attitude and practice of patients with type 2 diabetes regarding medicinal herbs, classical therapy and combination therapy (herbal and medicinal). The total score of attitude questions ranged from 6 to 18. Mean and standard deviation of attitude towards medicinal herbs and in the combination therapy group were $17.2 \pm 0.8$ and $15.4 \pm 2.3$, respectively. That is more than the mean and standard deviation (15.5 \pm 3.2$)$ of Bandar Abbas people's attitude towards herbal medicines in diabetes treatment in Marzban and et al. study. ${ }^{10}$ The percentage of favorable attitude in patients with medicinal herbs $(96 \%)$ was significantly higher than those of combination therapy (66.7\%) and drug treatment group (31.4\%). Patients' positive attitude toward herbal medicines treatment in diabetes was more than positive in the study of Yousef- pour and et al. (13.4\%) in Sari (17.4\%) and Talaei and et al. (29\%) study in Tehran (29\%), ${ }^{8,11}$ The results of studies by Sheikh Rabari and et al. in Kerman, ${ }^{12}$ Amaeze $\mathrm{O}$ and et al. in Lagos, Nigeria ${ }^{13}$ as in this study, positive attitudes are more prevalent in diabetic patients using medicinal plants to treat diabetes. The reason for the difference in the findings of this study with other studies can be due to differences in age and sex structure, sample size and cultural and socio-economic differences in the study population. The World Health Organization
(WHO) considers complementary and alternative medicine in each country a wide range of therapies that are not formally incorporated into that country's health system. These therapies have either come from past medical traditions or are based on contemporary concepts. Nowadays, herbs that have been the only cure for various human diseases for many years have been replaced by chemical drugs, but the side effects of some chemicals and the lack of treatment for some diseases have led people to revert to the same old tradition of using herbal remedies. One of the most important factors in people's tendency toward traditional medicine is modern medical complications or iatrogenic diseases (diseases that are the cause and origin of the medical science itself and the medical procedures).$^{14}$ In recent years, in the field of preventive medicine, the fourth level of prevention has been added to the famous three levels of prevention, namely the prevention of harm to the patient resulting from health interventions (drug side effects, etc.). ${ }^{15}$ The most important description of herbs in the community is that they are not harmful, meaning that if they do not cure, they will at least have no side effects. Of course, it is a misconception that medicinal herbs are harmless because they are natural, and even over-consumption of medicinal herbs can be a health hazard. On the other hand, the cost of treatment with chemical drugs is very high, especially for those who do not use the various insurance facilities and have to buy drugs at an affordable price, so 
using herbal medicines will be cheaper and at the same time cheaper. ${ }^{16}$ Using herbal remedies does not necessarily mean rejecting chemicals completely and having anti-science and anti-medical thinking, but in some cases using traditional medicine may be a better way to treat some diseases.

The results showed that there was no statistically significant relationship between desirable attitude toward treatment of diabetes with herbal medicines and age. This finding is consistent with the results of Yousef-pour and et al. study in Sari, ${ }^{8}$ Wanchai study in northern Thailand, ${ }^{17}$ Emine $\mathrm{K}$ study in Izmir, Turkey, ${ }^{12}$ and Naja $\mathrm{F}$ and et al. in Beirut. ${ }^{18}$ But it is inconsistent with the results of the Marzban and et al. study in Bandar Abbas,${ }^{10}$ Najm Abadi study in Tehran, ${ }^{19}$ Amaze $\mathrm{O}$ in Lagos Nigeria ${ }^{13}$ and the study of Al-Eidi S and et al. ${ }^{20}$ in Riyadh, Saudi Arabia. Also, favorable attitude to herbal treatment in the three study groups was not significantly correlated with gender, which is in line with the results of Yousef-pour and et al. in Sari, ${ }^{8}$ Najm Abadi in Tehran ${ }^{21}$ and Amaeze O in Lagos, Nigeria. ${ }^{13}$ But it did not match the results of the study by Marzban and et al. in Bandar Abbas, ${ }^{10}$ Emine $\mathrm{K}$ in Izmir, Turkey, ${ }^{12}$ and Naja $\mathrm{F}$ and et al. in Beirut ${ }^{18}$ This relationship was not significant for the desired attitude and level of education. This finding is consistent with the results of the Wanchai study in northern Thailand ${ }^{17}$ but is inconsistent with the results of the Marzban and et al. Study in Bandar Abbas, ${ }^{10}$ Najm Abadi in Tehran, ${ }^{19}$ and Amaze $\mathrm{O}$ in Lagos, Nigeria. ${ }^{13}$ The desired attitude had not signified cant relationship with marital status as well. This finding is consistent with the results of the Wanchai ${ }^{17}$ study in northern Thailand but did not match the results of the study of Yousef pour and et al. in Sari, ${ }^{8}$ Emine $\mathrm{K}$ in Izmir, Turkey, ${ }^{12}$ and Naja F et al. in Beirut. ${ }^{18}$ Also in this study, there was no significant relationship between desirable attitude to herbal treatment in the three study groups with occupation and family history of diabetes, which is in line with the results of Naja $\mathrm{F}$ et al. ${ }^{18}$ study in Beirut, Amaze $\mathrm{O}^{13}$ in Lagos Nigeria and AlEidi S study in Riyadh Saudi Arabia ${ }^{20}$ do not match. The favorable attitude to herbal treatment in the three study groups had a significant inverse relationship with the duration of the disease. The desirable attitude was seen in patients with less than 6years $(67.1 \%)$ and less than 5years $(71.1 \%)$ treatment. In the Wanchai study in northern Thailand, ${ }^{17}$ positive attitudes were also significantly higher in patients with less than $<10$ years. But studies by Yousef pour and et al. in Sari, ${ }^{8}$ Amaze $\mathrm{O}$ in Lagos, Nigeria, ${ }^{13}$ Naja $\mathrm{F}$ et al. in Beirut, ${ }^{18}$ and Emine $\mathrm{K}$ in Izmir, Turkey, ${ }^{12}$ showed a significantly higher positive attitude in patients with higher duration morbidity.

Patients' satisfaction was $95.9 \%$ with herbal treatment, $84.3 \%$ with combination therapy and $54.9 \%$ with medication. Patients' satisfaction with herbal treatment in our study was higher than those of Yousef pour and et al. study in $\operatorname{Sari}^{8}(51 \%)$, Talaei and et al. in $\operatorname{Tehran}^{11}(52 \%)$ and Sheikh Rabari and et al. in Kerman (69\%). ${ }^{12}$ The reasons for satisfaction with herbal treatment in these studies, as in our study, were reported higher treatment speed, better availability, and lower cost of medicinal herbs. The reason for the difference in the findings of this study with other studies can be due to differences in age and sex structure, sample size and cultural and socio-economic differences in the study population.

In this study, the most consumed were cinnamon (26.5\%), green tea $(14.7 \%)$, ginger $(9.8 \%)$, fenugreek $(9.8 \%)$, nettle $(6.9 \%)$ and turmeric $(6.9 \%) . \%)$ for the treatment of type 2 diabetes, which is consistent with the results of Najm Abadi and et al study. ${ }^{19}$ But in the study of Yousef pour et al. in Sari "Nettle plant", the study of Mekuria and et al. in Ethiopia ${ }^{22}$ and the study of Mohammed and et al in Babylon Iraq ${ }^{23}$ "garlic" was the most reported medicinal plant in the treatment of type 2 diabetes. In the herbal treatment group, parents and relatives were the most important source of knowledge $(45.1 \%)$ and in the combination therapy group, $60 \%$ were friends and acquaintances that were statistically significant. This finding is in line with the results of the Marzban and et al. study in Bandar Abbas ${ }^{10}$ and Mekuria et al in Ethiopia. ${ }^{22}$

\section{Conclusion}

Our study reported diabetic patients have a high attitude towards the use of herbal medicines in the treatment of diabetes in patients taking medicinal herbal. Patients with a shorter duration of treatment and disease had a higher attitude and performance than herbal medicines. The side effects of some chemicals and the lack of treatment have led people to revert to the same old tradition of using herbal remedies. One of the most important factors in people's tendency toward herbal medicines is modern medical complications or iatrogenic diseases.

\section{Acknowledgments}

Study is the result of the dissertation of the family medicine doctorate course and the approval of the medical ethics committee at IR.KUMS.REC.1397.722. In this way, the cooperation of the esteemed research deputy of Kermanshah University of Medical Sciences, management and staff of the University Diabetes Center is thanked and appreciated.

\section{Disclaimer}

None.

\section{Conflicts of interest}

None.

\section{Source of funding}

This article is the result of a thesis for obtaining a doctorate in family medicine and the approval of the Medical Ethics Committee under number IR.KUMS.REC.1397.722 with the financial and spiritual support of Kermanshah University of Medical Sciences.

\section{References}

1. Vahidi H, Ghoreishian S, Bashardoost N, et al. Study of Attitudes and behaviors of People in Yazd city Regarding Herbal Medicine Consumption in Diabetes. Tolooebehdasht. 2014;12(4):113-122.

2. Ng SH, Mohd Zain MS, Zakaria F, et al. Hypoglycemic and Antidiabetic Effect of Pleurotus sajor-caju Aqueous Extract in Normal and Streptozotocin-Induced Diabetic Rats. Papatheodorou K, editor. Biomed Res Int. 2015;2015:214918.

3. Reddy SS. Health outcomes in type 2 diabetes. Int J Clin Pract Suppl. 2000;(113):46-53.

4. Dehghan H, Mirzaei M, Mirzaei E, et al. Comparison of Therapeutic Effects of Linagliptin and Metformin in Patients with Type 2 Diabetes: A systematic Review and Meta-Analysis. Arumsj. 2018;18(1):21-33.

5. Hasani-Ranjbar S, Larijani B, Abdollah M. A systematic review of iranian medicinal plants useful in diabetes mellitus. Arch Med Sci. 2008;4(3):285-292.

6. Public I of M (US) $\mathrm{C}$ on the $\mathrm{U}$ of $\mathrm{C}$ and AM by the A. Complementary and Alternative Medicine in the United States. Ashington (DC): National Academies Press (US); 2005.

7. Grover JK, Yadav S, Vats V. Medicinal plants of India with anti-diabetic potential. J Ethnopharmacol. 2002;81(1):81-100. 
8. Yousofpour M, Kashi Z, Ahmadi Sani N, et al. Attitude and practice of diabetic patients towards Complementary/alternative medicine and related factors, Sari, 2014-2015. J Maz Univ Med Sci. 2016;26(136).

9. Zare Shahabadi A, Ebrahimi Sadrabadi F. Impact of Cognitive Factors on Treatment of Type 2 Diabetes in Yazd. Clin Psychol Stud. 2013;4(13):122 .

10. Marzban A, Barzegaran M, Delavari S, et al. Attitudes and Behaviors of People in Bandar-Abbas City about Herbal Medicine Consumption in Diabetes. Iran J Diabetes Lipid Disord. 2018;17(6).

11. Talaei B, Asghari G, Mirmiran P, et al. Knowledge, Attitude, and Practice of Diabetic Patients toward Herbal Products in Iran: A Cross-sectional Study. J Nutr Food Secur. 2019;4(3):161-169.

12. Karaman E, Erkin Ö, Senman S, et al. The use of herbal supplements by individuals with diabetes mellitus. J Pak Med Assoc. 2018;68(4):587594.

13. Amaeze OU, Aderemi-Williams RI, Ayo-Vaughan MA, et al. Herbal medicine use among Type 2 diabetes mellitus patients in Nigeria: understanding the magnitude and predictors of use. Int J Clin Pharm. 2018;40(3):580-588

14. Aghaei Atefeh, Khalili M. The social component associated with the tendency of patients to complementary and alternative therapies. Complement Med J. 2018;7(4).

15. Jamoulle M. Quaternary prevention, an answer of family doctors to overmedicalization. Int J Heal Policy Manag. 2015;4(2):61-64.
16. Paul Farmer. The Major Infectious Diseasesinthe World — To Treator Notto Treat? N Engl J Med. 2001;345:208-210.

17. Wanchai A, Phrompayak D. Use of complementary and alternative medicine among Thai patients with type 2 diabetes mellitus. J Integr Med. 2016;14(4):297-305

18. Use among diabetic patients in Beirut, Lebanon: A cross-sectional study. BMC Complement Altern Med. 2014;14(1):1-11.

19. Shahandokht N, Nojomi M, Moradilakeh M, et al. The Common Herb In Self Herbal Medication In Diabetic Patients Refer To Diabetes Medical Health Center. Iran J Diabetes Lipid Disord. 2014;13(5).

20. Al-Eidi S, Tayel S, Al-Slail F, et al. Knowledge, attitude and practice of patients with type 2 diabetes mellitus towards complementary and alternative medicine. J Integr Med. 2016;14(3):187-196.

21. Sheikhrabori A, Dehghan M, Ghaedi F, et al. Complementary and Alternative Medicine Usage and Its Determinant Factors Among Diabetic Patients: An Iranian Case. J Evidence-Based Complement Altern Med. 2017;22(3):449-454.

22. Mekuria AB, Belachew SA, Tegegn HG, et al. Prevalence and correlates of herbal medicine use among type 2 diabetic patients in Teaching Hospital in Ethiopia: A cross-sectional study. BMC Complement Altern Med. 2018;18(1):1-8

23. Mohammed AAAG, Al-aaragi ANH, Merzah MA. Knowledge, Attitude, and Practice Regarding Diabetic Mellitus among a Sample of Students at Technical Institute of Karbala. Med J Babylon. 2018;15(2):164-168. 